\title{
Parental Knowledge and Attitude Towards Early Orthodontic Treatment for Their Primary School Children
}

\author{
Vahid Moshkelgosha, ${ }^{1,2}$ Mahsa Kazemi, ${ }^{3,{ }^{*}}$ Hamidreza Pakshir, ${ }^{1,2}$ and Rasool Safari ${ }^{4}$ \\ ${ }^{1}$ Department of Orthodontics, School of Dentistry, Shiraz University of Medical Sciences, Shiraz, Iran \\ ${ }^{2}$ Orthodontics Research Center, Shiraz University of Medical Sciences, Shiraz, Iran \\ ${ }^{3}$ Student's Research Committe, School of Dentistry, Shiraz University of Medical Sciences, Shiraz, Iran \\ ${ }^{4}$ Student's Research Committe, School of Medicine, Shiraz University of Medical Sciences, Shiraz, Iran \\ "Corresponding author: Mahsa Kazemi, Student's Research Committe, School of Dentistry, Shiraz University of Medical Sciences, Shiraz, Iran. E-mail: \\ sahar.kazemi11@yahoo.com
}

Received 2016 June 06; Accepted 2016 September 20.

\begin{abstract}
Background: Malocclusion, one the most important oral health problem among children and young adults, leads to social stigma and psychological disorders. Early orthodontic treatment for children appears to be one of the efficient methods to prevent these consequences.

Materials and Methods: This cross-sectional study, which was conducted in Shiraz, city of Iran, comprised 1600 primary school children aged 7 and 8 years old from 16 schools in the 4 districts of Shiraz. Self-administered questionnaires, giving scores to parental knowledge and attitude towards early orthodontic treatment, were designed and distributed to the children to deliver them to their parents. The maximum possible mean score for both knowledge and attitude questions were.

Results: Out of 1600, 1026 (64\%) questionnaires were returned. The analysis revealed the mean score of parental knowledge and attitude as 0.78 and 0.38 respectively. The mean score of participants from high social class was significantly higher in the knowledge and attitude sections (Pvalue $<0.001$ ). Highly educated parents presented an appreciably greater level of attitude score (mean score: 0.43 , P value $<0.001$ ). A remarkable correlation of parental former orthodontic treatment with a routine and problem-based visit of a dentist was observed [odds ratio (OR):3.1, 95\% confidence interval (CI): 2.1 to 4.4 ] and (OR: 3.1, 95\% CI: 2.2 to 4.4 ) in order.

Conclusions: This study showed significant effect of higher social class on the parents' knowledge and attitude and also beneficial impact of higher educational level on parents' attitude. The parents, who were former orthodontic patient, were more concerned about their children's dentofacial health.
\end{abstract}

Keywords: Parents, Knowledge, Attitude, Orthodontic Treatment, Children

\section{Background}

Considering the normal position of teeth, which occurs in the context of an efficient relation to the alveolar process of the basal bone and appropriate relation with other adjacent and/or opposing teeth, malocclusion is defined as any deviation from this position and includes missing, teeth crowding, spacing, alteration of overjet, presence of openbite, and anterior maxillary and mandibular disformity. Malocclusion, as a major oral health problem, take the second place among most common dental disorders of children and young adults after dental caries (1-3). Dentofacial features play a pivotal role in social integration and interpersonal communication. While proper aesthetic occlusion leads to look more attractive, amplifying self-esteem, more acceptable and respected character among peer groups, and greater social achievements, malocclusion results in being teased and embarrassed, and consequently social rejection and inevitable psychological disorders $(1,4-8)$. Therefore, sev- eral different factors such as age, gender, parental and selfperception of dental appearance, and educational and socioeconomic status influence a person to apply orthodontic treatment. Among these factors, high social class and children are more concerned and less aware respectively $(3,5,9)$.

Orthodontic and dentofacial orthopedics specialty is a method of prevention, diagnosis, and correction of malocclusions due to skeletal and neuromuscular abnormalities related to developing or mature dentofacial structures (10). Orthodontic care whether performed due to the professional assessment or patient self-perception brings about beneficial effects, including aesthetic enhancement, functional improvement, and psychosocial wellbeing $(1,6$, $10,11)$.

Not only the majority of patients referring to orthodontic professionals consists of children, but also the pre-adolescent stage of life is a crucial period during which dental health development is occurring. These important issues urge the need to seek out the most efficient 
and effective measurements to establish better dentofacial health and function during this period. Previous studies declared vital role of parents in performing orthodontic management for their children, interestingly having similar viewpoints as dentists' evaluation of dentofacial deformities $(1,4,12)$. The former studies have illustrated that parents choose orthodontic treatment for promoting their children oral health and function and limiting social stigma as well. Evidence has revealed that the parents, who had been orthodontic patients beforehand or interested to undergo this treatment now, are more approving of implicating this treatment for their children $(3,9,13)$.

Thus, determination of parents' knowledge and attitudes to early appliance of orthodontic treatment for their children are of great value. Meanwhile, scarce data has existed in Shiraz, according to this topic. Hence, we conducted the present survey to investigate this important issue among parents of school children aged 7 and 8 in four different districts of Shiraz, south of Iran, which may improve dental health policies and services to foster early childhood orthodontic treatment and establish better utilization of resources.

\section{Materials and Methods}

\subsection{Study Design}

The present study is a descriptive cross-sectional study, which is conducted between September 2015 and December 2015, in all four districts of Shiraz. According to this categorization, district 1includes west and south-west of Shiraz, district 2 accounts for north and north-west, district 3 stands for east and north-east, and district 4 represents south and south-east. These geographical districts were taken into account as proxy parameters of social class, while district 1 and 2 represent higher social class people and the people with lower socioeconomic status dwelling district 3 and 4.

This study was approved under the supervision of the ethics committee of Shiraz university of medical sciences. The approval of questionnaire distribution was signed by boards of educational and training organization.

Subdivisions of main educational and training organization of Shiraz are categorized into four in regards to the four geographical districts. Four schools under the supervision of any of four subdivisions was selected via random multi-stage sampling by confirmation of a professional statistician. Eight of these sixteen schools were female school and the other eight were male school. Therefore, in each of these four district 2 male and 2 female schools were considered and in every single school presence of 100 children aged 7 and 8 were assumed. Thus, 1600 questionnaires were distributed to these school children through their teachers to hand in them to their parents. After that 1026 (64\%) of all questionnaires were returned.

The exclusion criteria were the unwilling parents to participate in this study and the questionnaires not being returned due to any reasons.

\subsection{Questionnaire Characteristics}

A structured self-administered questionnaire was designed specifically for this study by the orthodontic faculty member of the Shiraz orthodontic department and revised by another orthodontist. It consists of four sections: section1 includes information about the study design and purpose for participants, in section 2 questions of demographic characteristics of the parents such as age $(\leq 40$ and $>40$ ), gender, site of residency (district 1, 2,3,4), educational status ( diploma and high school, supra-diploma and bachelor, master and PhD), number of children, satisfaction of their dentition, history of orthodontic treatment of themselves or their children, and desire of undergoing orthodontic care for themselves and their children were asked. The section 3 includes 10 questions, analyzing parents' attitudes and in the section 4,10 questions about parents' knowledge were proposed. Answers to these 20 questions were indicated with yes, no, and don't know. Regarding these 3 options, 3 scores, including +1 (correct answer), 0 (don't know), and -1 (wrong answer) were given to each question. Hence, maximum score of each of these 2 sections would be 10 . All questions are in simple and colloquial words so that everyone would be able to understand the concept easily.

Face validity of the questionnaire was evaluated through random selection of 10 parents, referring to the orthodontic department of Shiraz university. They were asked how clear the questions are, how long and ambiguous they are as well. Subsequently to assess the validity, content validity ratio and content validity index were used under supervision of a statistician and orthodontists.

The reliability of the questionnaire was ensured via handing out 30 questionnaires to 30 parents, having their children visited at the orthodontic department of Shiraz university, to fill the questionnaires and then collecting them. After a period of 30 days, the questionnaires were given to the same people to compare with their earlier responses through using the test Cronbach.

\subsection{Statistical Analysis}

Data analysis was done by using SPSS (statistical package for social sciences) version 19. Descriptive analysis of section 2 was performed. Mean \pm SD of section 3 and 4 , representatives of attitudes and knowledge of parents, were 
explored totally and also with respect to age, gender, educational and socioeconomic status, and parental history of previous orthodontic treatment. The correlation of dissatisfaction and former orthodontic treatment of parents with routine visit of dentist and orthodontic care for their children were pointed out after adjustment of other influencing factors such as educational and socioeconomic status. This correlation was investigated with Cochran's mantel hanszeal test. Categorical and nominal variables were tested by Chi square and Fisher's exact test (2-sided). Quantitative data were analyzed by the student's t test. All pvalues less than 0.05 were considered significant.

\section{Results}

Prior to analysis of demographic data, missing values of these 1026 questionnaires were excluded. Participants who mentioned their age and sex were 990 and 1007 respectively. Parents who made evident their educational status and district of residency were 995 and 1007 in order ( Table 1).

Regarding the sections of attitude and knowledge, the mean scores of total responses were 0.38 (SD: 0.27) and 0.78 (SD: 0.21 ) respectively (Table 2 ). The mean score of participants in regards to socioeconomic status not only in attitude ( $\mathrm{P}$ value $<0$. 001), but also in knowledge ( $\mathrm{P}$ value $<0$. 001) section were statistically significant. It was also remarkably significant in educational levels ( $\mathrm{P}$ value $<0$.

Table 1. Demographic Data of the Parents

\begin{tabular}{|c|c|}
\hline Variable & No. (\%) \\
\hline \multicolumn{2}{|l|}{ Age } \\
\hline$\leq 40$ & $57(8.1)$ \\
\hline$>40$ & $415(41.9)$ \\
\hline \multicolumn{2}{|l|}{ Gender } \\
\hline Male & $339(33.7)$ \\
\hline Female & $668(66.3)$ \\
\hline \multicolumn{2}{|l|}{ Educational status } \\
\hline Diploma and high school & $267(26.8)$ \\
\hline Supra-diploma and bachelor & $524(52.7)$ \\
\hline Master and PhD & $204(20.5)$ \\
\hline \multicolumn{2}{|l|}{ Socioeconomic status } \\
\hline District1 (west and south-west) & $260(25.8)$ \\
\hline District2 (north and north-west) & $277(27.5)$ \\
\hline District3 (east and north-east) & $267(26.5)$ \\
\hline District4 (south and south-east) & $203(20.3)$ \\
\hline
\end{tabular}

001) and parental previous history of orthodontic treatment (P value $<0.05$ ) in attitude section (Table 3 ).

After considering the effects of educational and socioeconomic status, association of parental dissatisfaction about their dental appearance with routine visit of dentist (OR: 0.9, 95\% CI: 0.6 to 1.2 ) and history of previous visiting of a dentist due to their children orofacial deformity (OR: 1.0 , 95\% CI: 0.8 to 1.4) failed to exhibit any significances. Exploring parents' interest to undergo orthodontic treatment themselves relation with taking their children to the dentist either due to routine visit (OR:1.0, 95\% CI:0.8 to 1.4) or due to the presence of orofacial deformity (OR: 1.0, 95\% CI: 0.7 to 1.3 ) revealed no significant correlation. However, parental former orthodontic treatment's association with the routine and problem-based dentist visit was substantially significant, (OR: 3.1, 95\% CI: 2.1 to 4.4 ) and (OR: 3.1, 95\% CI: 2.2 to 4.4 ) in order.

Nearly $38 \%$ of parents were dissatisfied with their dentofacial appearance and $36 \%$ stated the desire to undergo orthodontic treatment. Of parents, 29.5\% were former orthodontic patients. Parents who took their children to go for the routine dentist visit were $69.2 \%$. Regarding the attitude of parents, $28.1 \%$ of responses disclose unacceptable viewpoints about inaccurate habits (thumbsucking, nail-biting, pen-biting, and oral breathing) of their children lead to orofacial abnormalities. Meanwhile, in knowledge section, only $45.5 \%$ of respondents demonstrate awareness that the first orthodontist appointment is recommended at age $7-8$.

\section{Discussion}

The purpose of the present study was to assess parental knowledge and attitude about early orthodontic treatment for their children that we found a mean score for each of these two was influenced by socioeconomic status, whereas high social class presented a markedly higher level of acceptable attitude and knowledge. The score of attitude was appreciably higher among highly educated people. While the finding which exhibit the beneficial effect of high socioeconomic status in enhancing parents' knowledge were in line with most studies (14-16), and refuted with one study (17), as far as our knowledge this study exhibited the beneficial effects of both high educational and social class in improving of parents' attitude for the first time in Iran. The overall score of parents' attitude was highly lower than their knowledge, suggesting that there are parents who know about this issue but their knowledge existed insufficient to modify their attitude. We observed greater range of accurate attitude among parents with having previous orthodontic treatment for themselves, which was consistent with a previous survey (12). 
Table 2. The Mean Score of Parents' Responses to Each Question of the Knowledge and Attitude Section

\begin{tabular}{|c|c|c|}
\hline & Question & Mean Score (SD) \\
\hline \multirow{10}{*}{ Knowledge } & $\begin{array}{l}\text { 1- Orthodontic treatment by removable appliance can resolve mandibular deformities and prevent surgical treatment in } \\
\text { the future. }\end{array}$ & $0.779(0.203)$ \\
\hline & $\begin{array}{l}\text { 2- Girls, comparing to boys, should undergo orthodontic treatment at an earlier age because they reach puberty period } \\
\text { sooner. }\end{array}$ & $0.780(0.206)$ \\
\hline & 3- Orthodontic treatment means putting fixed wire and signet over the teeth. & $0.780(0.206)$ \\
\hline & 4- Early orthodontic treatment in childhood can prevent the need for later treatment. & $0.781(0.206)$ \\
\hline & 5- Orthodontic treatment is performed in different ways in adults and children. & $0.781(0.206)$ \\
\hline & $\begin{array}{l}\text { 6- When primary teeth exfoliate prematurely, space maintenance device could be applied to prevent secondary dentofacial } \\
\text { deformities. }\end{array}$ & $0.780(0.206)$ \\
\hline & 7- Dentofacial abnormalities are not preventable and treatable because they are genetically inherited. & $0.780(0.206)$ \\
\hline & 8- If permanent teeth are erupted not in alignment with others, it can be corrected by removing primary teeth. & $0.781(0.206)$ \\
\hline & $\begin{array}{l}\text { 9- The main reasons of dentofacial abnormalities are bad habits, such as oral respiration, thumb sucking, and wrong sleep } \\
\text { position. }\end{array}$ & $0.780(0.206)$ \\
\hline & 10- The orthodontic treatment in some of the children should be performed in 2 separate stages. & $0.780(0.206)$ \\
\hline \multirow{10}{*}{ Attitude } & 1- If any of my child's primary teeth has pain or caries, I remove it because it is primary and transient. & $0.380(0.274)$ \\
\hline & 2-I take my child to visit the dentist to check the need for orthodontic care at age 7 or 8. & $0.380(0.274)$ \\
\hline & 3-I will take my child to perform orthodontic treatment only if he/she would pass puberty period. & $0.380(0.274)$ \\
\hline & 4- To begin orthodontic treatment for our children, we wait till their wisdom teeth erupt. & $0.381(0.274)$ \\
\hline & 5- If my children have oral respiration we take them to the dentist to evaluate dentofacial abnormalities. & $0.380(0.274)$ \\
\hline & 6- If I remove my child's primary tooth before it becomes mobile, the permanent teeth would erupt more aligned. & $0.380(0.274)$ \\
\hline & 7- If my child has mandibular deformities I will wait till he/she becomes an adult after that,we try for surgical intervention. & $0.380(0.274)$ \\
\hline & $\begin{array}{l}\text { 8- Because my child has a bad habit of thumb sucking, I take him/her to the dentist as soon as possible to prevent } \\
\text { dentofacial problems. }\end{array}$ & $0.380(0.274)$ \\
\hline & 9- If my child needs orthodontic management I will do that even if he/she resists. & $0.380(0.274)$ \\
\hline & 10-To begin orthodontic treatment I wait till all his/her permanent teeth erupt completely. & $0.379(0.274)$ \\
\hline
\end{tabular}

Seeking out correlation of three parental characteristics such as dissatisfaction of their dental arrangement, desire to undergo orthodontic treatment, and past history of self-orthodontic management with routine and orofacial problem-based dentist visit for their children failed to reveal any remarkable differences except for the third factor. A study proved significant associations of these three parental factors with orthodontic need and orthodontist visit for their children (12). Our result may be interpreted in this way that parents disregarding their dissatisfaction and desire care about their children's oral health, however the difference appears when they have experienced this kind of treatment themselves. A report in Finland supported our result, indicating no significant link between parents' dissatisfaction and their children orthodontic need (18).

We selected parents of children aged 7 and 8 because the best recommended age for first orthodontic appointment is this age. Meanwhile the children of this age are not capable of expressing their opinions about this problem until reaching age 10 - 12 which urges the need for choosing parents as their guardians/caregivers $(18,19)$. Approximately half of the parents were aware of this issue, while in a study most of parents thought this was the best age (18). Interestingly a previous study, conducted in Shiraz with a similar sample size and setting, observed only one third of parents aware of this recommended age for the first orthodontist visit (14). We speculated the reasons for difference as follows: different educational level of participating parents, including age 9 in their study while our study investigated only age 7 and 8 children's parents, or may be concluded from this result that parental knowledge and awareness about their children's oral health has promoted during these 7 years in Shiraz.

We tried to minimize the potential bias of every stage of conducting this study, including random multistage sampling of schools to prevent selection bias, blinding statistician to parents' responses, and non-given or- 
Table 3. Parental Knowledge and Attitude Towards Early Childhood Orthodontic Treatment

\begin{tabular}{|c|c|c|c|}
\hline & Variable & Mean Score (SD) & P Value \\
\hline \multirow{18}{*}{ Knowledge } & Age & & 0.388 \\
\hline & $\leq 40$ & $0.78(0.21)$ & \\
\hline & $>40$ & $0.79(0.20)$ & \\
\hline & Gender & & 0.542 \\
\hline & Male & $0.78(0.20)$ & \\
\hline & Female & $0.77(0.21)$ & \\
\hline & Educational status & & 0.247 \\
\hline & Diploma and high school & $0.77(0.21)$ & \\
\hline & Supra-diploma and bachelor & $0.78(0.22)$ & \\
\hline & Master and PhD & $0.80(0.16)$ & \\
\hline & Socioeconomic status & & 0.000 \\
\hline & District 1 (west and south-west) & $0.81(0.20)$ & \\
\hline & District 2 (north and \&north-west) & $0.80(0.17)$ & \\
\hline & District 3 (east and north-easth) & $0.76(0.23)$ & \\
\hline & District4(south and south-east) & $0.74(0.21)$ & \\
\hline & Parental previous history of orthodontic treatment & & 0.097 \\
\hline & Yes & $0.80(0.20)$ & \\
\hline & No & $0.77(0.21)$ & \\
\hline \multirow{18}{*}{ Attitude } & Age & & 0.383 \\
\hline & $\leq 40$ & $0.39(0.27)$ & \\
\hline & $>40$ & $0.37(0.27)$ & \\
\hline & Gender & & 0.744 \\
\hline & Male & $0.38(0.27)$ & \\
\hline & Female & $0.38(0.27)$ & \\
\hline & Educational status & & 0.000 \\
\hline & Diploma and high school & $0.33(0.28)$ & \\
\hline & Supra-diploma and bachelor & $0.38(0.27)$ & \\
\hline & Master and $\mathrm{PhD}$ & $0.43(0.27)$ & \\
\hline & Socioeconomic status & & 0.000 \\
\hline & District 1 (west and south-west) & $0.46(0.26)$ & \\
\hline & District 2 (north and north-west) & $0.45(0.26)$ & \\
\hline & District 3 (east and north-east) & $0.31(0.28)$ & \\
\hline & District 4 (south and south-east) & $0.28(0.26)$ & \\
\hline & Parental previous history of orthodontic treatment & & 0.013 \\
\hline & Yes & $0.41(0.27)$ & \\
\hline & No & $0.37(0.28)$ & \\
\hline
\end{tabular}

thodontic and malocclusion information to children before and during the distribution of questionnaires. One of our study limitation was that we were unable to ensure that parents filled the questionnaires without getting help from the Net, books, or any other sources. We suggest organizing more studies to evaluate parents' attitude and com- 
pare it with their knowledge about the early childhood appliance of orthodontic treatments. Our results declared that there is still a long way to pave to reach optimal levels of knowledge and attitude among parents, especially those of lower educational and social class, about this topic which could be received to some extent via more popular communicational media such as television and radio programs, magazines and newspapers, and informational brochures delivering to patients at dentists' offices.

\subsection{Conclusion}

This study showed significant impacts of higher socioeconomic and educational status on parents' attitude and substantial effect of higher socioeconomic status on parents' knowledge. The parents with previous orthodontic treatment for themselves demonstrated noticeably higher level of acceptable attitude about their children's orthodontic need. There were no significant associations of parent's age and gender with their knowledge and attitude about this issue. This study existed to contribute healthcare authorities and parents to foster implication of early childhood orthodontic treatment.

\section{Acknowledgments}

This study is derived from the undergraduate thesis with No.11601 in the school of dentistry, Shiraz university of medical sciences.

\section{References}

1. Sharma A, Menon I, Aruna D, Dixit A. Prevalence of Malocclusion and Treatment Needs Among 12 to 15 Years Old School Children in Muradnagar Uttar Pradesh. IOSR J Dental Med Sci (IOSR-JDMS). ;1(14):60-5.

2. Jha K, Saha S, Gv J, Narang R, Biswas G, Sood P, et al. Prevalence of Malocclusion and its Psycho-Social Impact among 12 To 15-Year-old School Children in Lucknow City.J Clin Diagn Res. 2014;8(10):36-9. doi: 10.7860/JCDR/2014/9814.5000. [PubMed: 25478444].

3. Dogan AA, Sari E, Uskun E, Saglam AM. Comparison of orthodontic treatment need by professionals and parents with different sociodemographic characteristics. Eur J Orthod. 2010;32(6):672-6. doi: 10.1093/ejo/cjp161. [PubMed: 20299423].

4. Al-Sarheed M, Bedi R, Hunt NP. The views and attitudes of parents of children with a sensory impairment towards orthodontic care. Eur J Orthod. 2004;26(1):87-91. [PubMed:14994887].

5. Abu Alhaija ES, Al-Nimri KS, Al-Khateeb SN. Self-perception of malocclusion among north Jordanian school children. Eur J Orthod. 2005;27(3):292-5. doi: 10.1093/ejo/cjh094. [PubMed: 15947230].
6. Oland J, Jensen J, Elklit A, Melsen B. Motives for surgical-orthodontic treatment and effect of treatment on psychosocial well-being and satisfaction: a prospective study of 118 patients. J Oral Maxillofac Surg. 2011;69(1):104-13. doi: 10.1016/j.joms.2010.06.203. [PubMed: 21050649].

7. Krisztina MI, Sorana R, Réka G, Katalin V. Evaluation of Child Selfperception Regarding Their Oro-dental Status. Acta Med Marisiensis. 2013;59(5) doi: 10.2478/amma-2013-0061.

8. Nagarajan S, Pushpanjali K. The relationship of malocclusion as assessed by the Dental Aesthetic Index (DAI) with perceptions of aesthetics, function, speech and treatment needs among 14- to 15 year-old schoolchildren of Bangalore, India. Oral Health Prev Dent 2010;8(3):221-8. [PubMed: 20847999].

9. Wedrychowska-Szulc B, Syrynska M. Patient and parent motivation for orthodontic treatment-a questionnaire study. Eur J Orthod. 2010;32(4):447-52. doi: 10.1093/ejo/cjp131. [PubMed: 20008018].

10. Abeleira MT, Pazos E, Ramos I, Outumuro M, Limeres J, Seoane-Romero J, et al. Orthodontic treatment for disabled children: a survey of parents' attitudes and overall satisfaction. BMC Oral Health. 2014;14:98. doi: 10.1186/1472-6831-14-98. [PubMed: 25096027]

11. Tessarollo FR, Feldens CA, Closs LQ. The impact of malocclusion on adolescents' dissatisfaction with dental appearance and oral functions. Angle Orthod. 2012;82(3):403-9. doi: 10.2319/031911-195.1. [PubMed: 21942720].

12. Pratelli P, Gelbier S, Gibbons DE. Parental perceptions and attitudes on orthodontic care. Br J Orthod. 1998;25(1):41-6. doi: 10.1093/ortho/25.1.41. [PubMed: 9547974].

13. Momeni Danaei S, Salehi P. Association between normative and self-perceived orthodontic treatment need among 12- to 15-yearold students in Shiraz, Iran. Eur J Orthod. 2010;32(5):530-4. doi 10.1093/ejo/cjp139. [PubMed: 20106996].

14. Danaei SM, Oshagh M, Pajuhi N, Ghahremani Y, Bushehri GS. Assessment of parental awareness about malocclusion in Shiraz, Islamic Republic of Iran. East Mediterr Health J. 2011;17(7):599-603. [PubMed: 21972484].

15. Reichmuth M, Greene KA, Orsini MG, Cisneros GJ, King GJ, Kiyak HA Occlusal perceptions of children seeking orthodontic treatment: impact of ethnicity and socioeconomic status. Am JOrthod Dentofacial Orthop. 2005;128(5):575-82. doi: 10.1016/j.ajodo.2004.09.021. [PubMed: 16286204].

16. Sivertsen R. How different social classes benefit from the subsidized orthodontic services in Norway. EurJOrthod. 1981;3(4):273-7. [PubMed: 6945998].

17. Milen A, Tala H. Social inequity in oral health-a newly awakened problem. Proc Finn Dent Soc. 1986;82(5-6):260-6. [PubMed: 3823096].

18. Pietila T, Pietila I. Parents' views on their own child's dentition compared with an orthodontist's assessment. EurJOrthod. 1994;16(4):30916. [PubMed: 7957656].

19. Horowitz HS, Cohen LK, Doyle J. Occlusal relations in children in an optimally fluoridated community. IV. Clinical and socialpsychological findings. Angle Orthod. 1971;41(3):189-201. doi 10.1043/0003-3219(1971)041<0189:ORICIA>2.0.CO;2. [PubMed: 5283667]. 